Vol. 1, No. 2, 2020

\author{
Mykola Zhuk, Volodymyr Kovalyshyn, Volodymyr Hilevych \\ Lviv Polytechnic National University \\ 12, Stepan Bandery Str. Lviv, 79000, Ukraine
}

(C) M. Zhuk, V. Kovalyshyn, V. Hilevych, 2020

https://doi.org/10.23939/tt2020.02.044

\title{
FORECASTING OF URBAN BUSES DWELLING TIME AT STOPS
}

\begin{abstract}
Summary. Intelligent Transport Systems in urban conditions is one of the solutions to reduce congestion of vehicles and the amount of harmful emissions. An important component of ITS is the assessment of the duration of a public transport trip. It is necessary to focus on the study of the duration of the bus (the duration of traffic between stops and the dwelling time). In this paper, the authors focused on determining the dependence of the duration of buses at stops depending on the demand of passengers. The dwelling time of buses at stops is not considered independent of the duration of the journey. The duration of the bus is the periods of time when the buses wait at the stops, and the travel time, which is the duration of the bus between each two stops. The study was conducted on the bus route \#3A in Lviv. To determine the dwelling time of the bus at stops, it is necessary to take into account information about passengers and the trajectory of buses. The obtained data can increase the accuracy of forecasting in different traffic situations in comparison with the most modern methods.
\end{abstract}

Key words: intelligent transport systems, dwelling time, transit time, bus, stop, traffic conditions.

\section{INTRODUCTION}

An important aspect of Intelligent Transport Systems is to ensure the accuracy of information on the duration of public transport. Knowing the travel time of scheduled vehicles, you can reduce the waiting time for passengers and attract more people to use public transport. Existing approaches have two main limitations in predicting bus travel time [1-5]. First, the large number of factors influencing traffic and the limited amount of real-time travel duration data in modern cities make it difficult to accurately predict travel time. The second - mostly travel time of public transport, under the influence of various factors, has different patterns. However, little research has focused on how to separate different areas of the route and build independent models for them (eg traffic on different sections of roads or streets). A new segmental approach for forecasting travel time of public transport is proposed, using the model of real bus traffic data, which are defined in different segments of bus routes. The demand of passengers and the downtime of the bus at public transport stops are estimated. Compared with existing methods, experimental results show that this approach increases the accuracy of prediction of travel time [6-10].

\section{RESEARCH STATEMENT}

Providing accurate information about the transit and the dwelling time of public transport allows to reduce the passengers waiting time and to attract most people to use public transport. The authors proposed a new segment approach for forecasting travel time of public transport. It is used the real bus traffic data, which are defined in different segments of bus routes [11].

As the number of buses in urban areas is constantly growing, traffic congestion has become an important problem in many cities. The development of Intelligent Transport Systems is one of the solutions to reduce the pollution in transport. Estimating the buses travel time is an important component of Intelligent Transport Systems, as it provides accurate information about passengers travel in real time. An 
Intelligent System can reduce passengers waiting time instead of predefined schedules. It can also improve the quality of system maintenance by instantly adjusting the shipment schedule when unforeseen events occur.

Among the various systems of public transport bus network is the most difficult and the most common in modern cities that can use the existing road infrastructure and has lower operating costs. Therefore, to improve the quality of public transport services it is necessary to focus on the following problem - how to accurately determine the travel time or dwelling time of buses. Determining bus travel time in real time has many advantages, including passenger planning [12-17], where trips are planned by calculating the duration of the trip to each destination and optimizing the route [18]. With this information system operators can design and adjust the data according to the estimated duration of the trip. Based on that, many existing studies predicting the travel time of buses have achieved varying degrees of success [17-19]. However, the continuation of these studies will make it possible to more accurately predict the travel and dwelling times of buses.

Estimating the duration of bus routes has attracted many researchers and planners of Intelligent Transport Systems to solve this problem. Various models and methods for predicting bus traffic, time or speed of arrival are proposed.

Existing approaches are divided into three parts based on models, influencing factors and methods of route construction. The following is an overview and comparison of some of them.

Artificial neural network (ANN) is a popular approach to solving complex nonlinear problems that is commonly used to predict the travel time. The authors [19] proposed two ANN models to predict the buses arrival time as a basis for route construction, using travel times and stops. Their research results show that the two models based on ANN have quite good performance. Studies by other authors [14] also show that ANN-based models provide better performance by comparing the accuracy of trip duration prediction with average data and regression methods.

Support vector method (SVM) is a specific type of statistical learning algorithm that has a number of properties, such as the ability to control decision-making functions and provide nonlinear decisions. Recently, SVM has been used as a useful method for predicting the travel time. For example, studies [17-19] have shown that SVM models outperform ANN using averages and time series methods.

Kalman filtering is an effective evaluation procedure because it has the ability to update the timedependent state. New observations become available constantly. Researchers [3,10] introduced Kalman filtering methods to predict the duration of the bus, using real-time data.

On the buses travel time is influenced by various factors such as different weather conditions [11-12], time changes of peak and non-peak hours [6, 13-15], information about boarding passengers $[3,11,16]$, traffic conditions in the mode real time [17-18]. Compared to the model based on GPS data, forecasting accuracy is improved by entering speed data and passenger data during rush hours on weekdays. Taking both factors into account in one model is an effective way to reduce the uncertainty of road weather forecasting results [16]. It can be noted that there are a small number of studies that take into account the impact of real-time road conditions on the travel time of the bus and the relationship between them.

The objectives of the study are to propose a new approach based on segmentation, which includes data on traffic flow in real time. The authors propose a methodology for segmenting the bus route, which can rely on information about GPS data and field research data. Real-time traffic conditions are the main factors influencing on the travel time and the number of passengers at stops is the main factor influencing the time spent at the stop, it is necessary to recognize two independent schemes of travel time and time based on different traffic data in real time.

The study was conducted on bus route \#3A in Lviv, which is divided into three segments to predict the total duration of the bus trip in order to take into account traffic conditions (Fig. 1).

The route connects two terminals: Terminal A - shopping center "King Cross Leopolis" (southern part of the city); Terminal B - Square "Rizni" (city center). Table 1 shows the main characteristics of the bus line \#3A. 


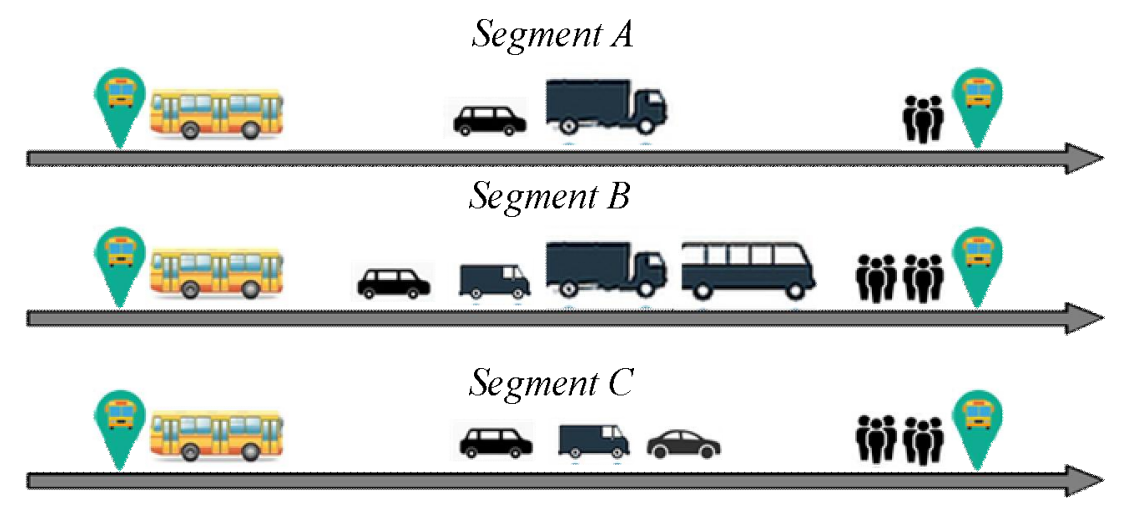

Fig. 1. Examples of bus traffic under different conditions: Segment (A) main street, load level $z \leq 0.5$; Segment (B) main street, load level $z \geq 0$.7; Segment (C) streets in the central part, load level $z \geq 0.5$

Table 1

The main characteristics of the bus line \#3A

\begin{tabular}{|c|c|}
\hline Work time & From 6:15 (Terminal A) / 7:00 (Terminal B) to 23:00 \\
\hline Route length (for direction) & $18.54 \mathrm{~km}(9.26 \mathrm{~km} / 9.28 \mathrm{~km})$ \\
\hline Travel time & $30-60 \mathrm{~min}$ \\
\hline Number of stops & $17 / 17$ stops (to the center / from the center) \\
\hline Distance between stops & from $350 \mathrm{~m}$ to $1000 \mathrm{~m}$ \\
\hline Number of buses on the route & $12-14$ \\
\hline Type of buses on the route & 12 -meter low-floor \\
\hline
\end{tabular}

Data on the time of travel by bus were obtained from GPS data and refer to the working days of each week. Data of the bus route \#3A was collected during the monitoring of bus traffic using GPS and blank method of passenger traffic research. The data collected include the departure time from the initial stop and the arrival time to the final stop.

\section{MAIN PART}

\subsection{Study of passenger demand at stops of route \#3A}

As a result of research conducted at public transport stops, the value of the number of passengers boarding the bus \#3A on the divided segments along the route was obtained. The study of the performance of the route \#3A at the stop "Prospekt Svobody" (segment C) is shown in Fig. 2, 3.

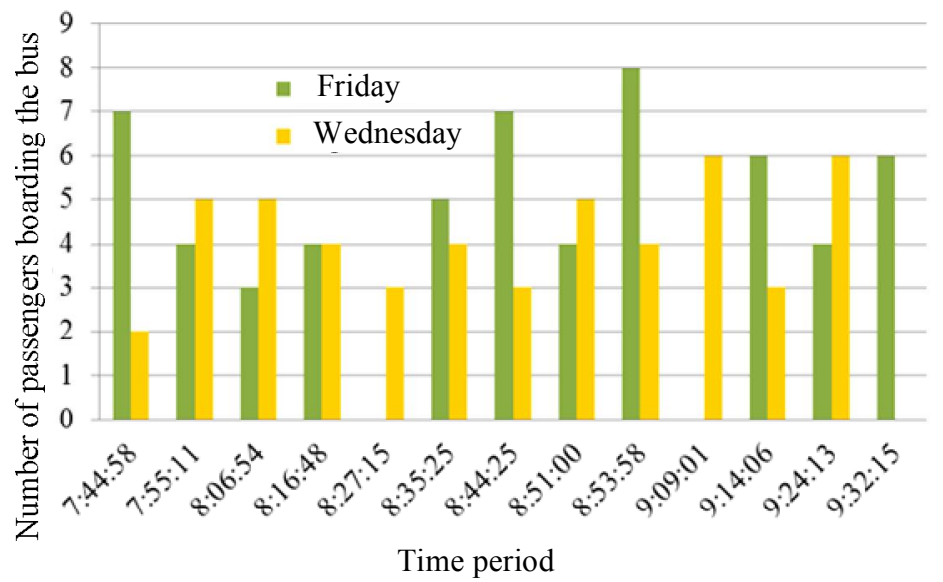

Fig. 2. Number of passengers boarding the bus \#3A at stop "Prospekt Svobody" (segment C) 


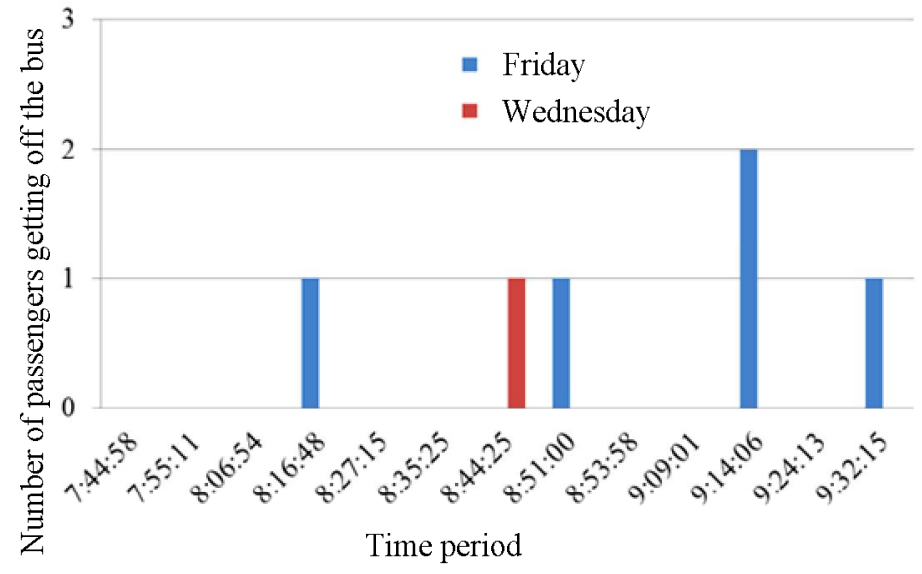

Fig. 3. Number of passengers getting

off the bus \#3A at stop "Prospekt Svobody" (segment C)

As can be seen from the Fig. 2, 3, the demand of passengers at the stop "Prospekt Svobody" (segment $\mathrm{C}$ ) reaches a maximum value of 8 passengers on Friday and the minimum -2 passengers on Wednesday. The number of passengers left is insignificant, as this is the first stop on the route after the final. On the average at the given stop come in 5 passengers, turns out - 1 passenger.

The study of the performance of the route \#3A at the stop "Shota Rustaveli" (segment C) is shown in Fig. 4, 5.

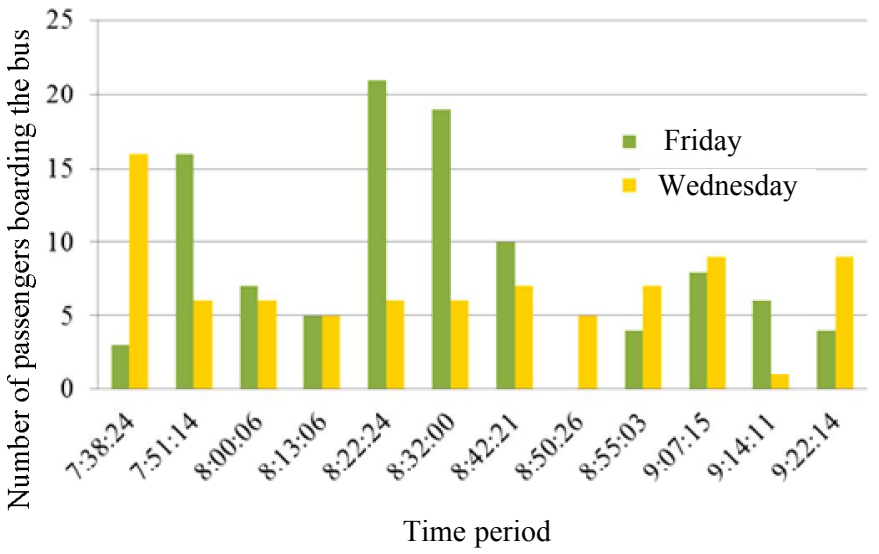

Fig. 4. Number of passengers boarding the bus \#3A at stop "Shota Rustaveli" (segment C)

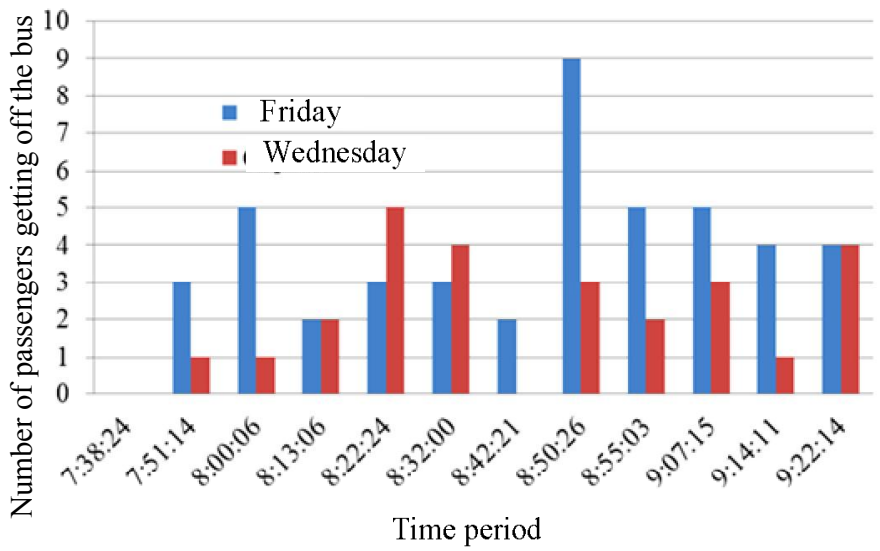

Fig. 5. Number of passengers getting off the bus \#3A at stop "Shota Rustaveli" (segment C) 
As can be seen from the figures, passenger demand at stop "Shota Rustaveli" (segment C) reaches a maximum of 22 passengers on Friday and a minimum of 3 passengers on Wednesday. The number of departing passengers reaches a maximum of 9 passengers on Friday and a minimum of 1 passenger on Wednesday. On the average at the given stop come in 9 passengers, turns out -4 passengers.

The study of the performance of the route \#3A at the stop "Childrens Railway" (segment B) is shown in Fig. 6, 7.

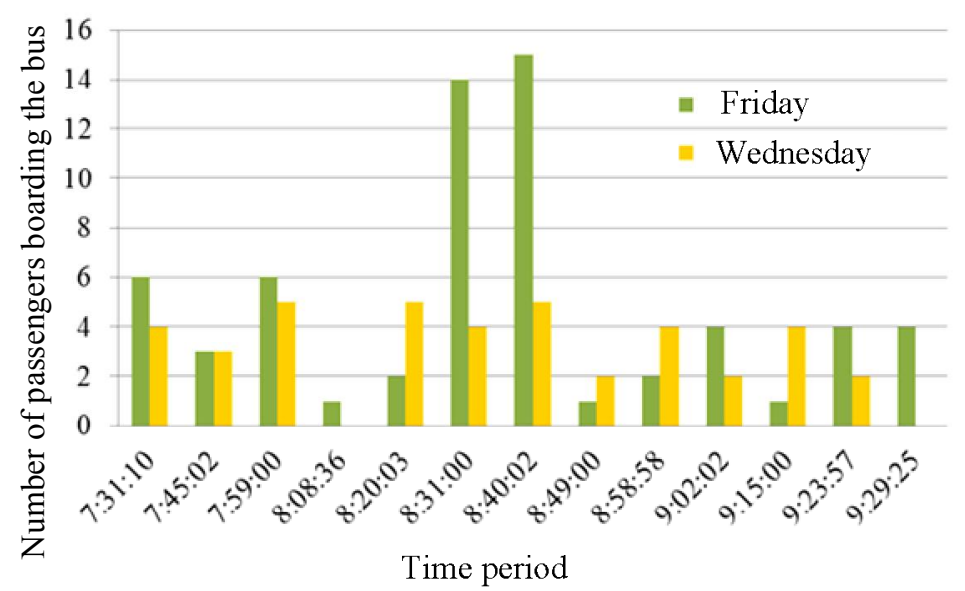

Fig. 6. Number of passengers boarding the bus $\# 3 A$ at stop "Childrens Railway" (segment B)

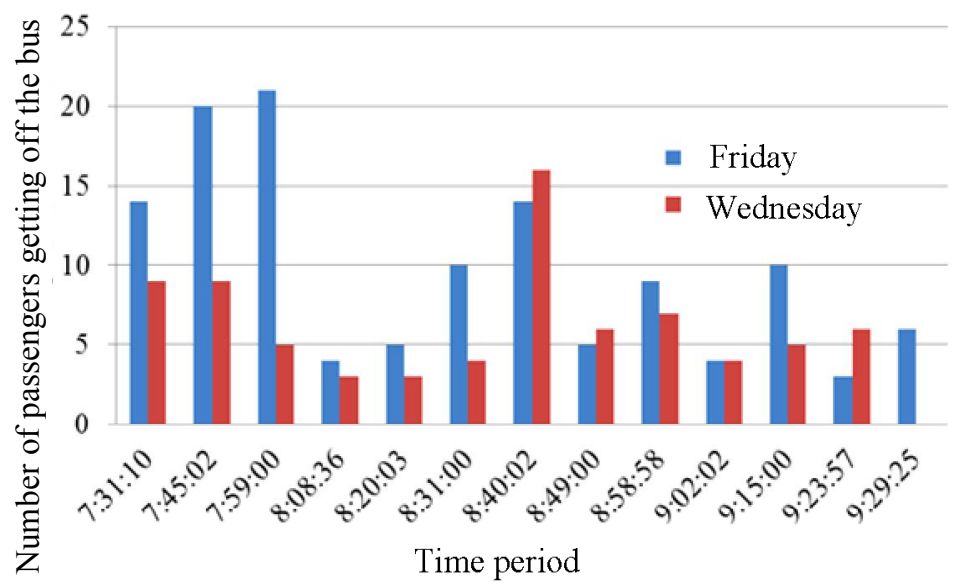

Fig. 7. Number of passengers getting off the bus $\# 3 A$ at stop "Childrens Railway" (segment B)

As can be seen from the figures, the demand for passengers at stop "Childrens Railway" (segment B) reaches a maximum of 15 passengers on Friday and a minimum of 1 passenger on Friday as well. The number of departing passengers reaches a maximum of 21 passengers on Friday and a minimum of 3 passengers on Wednesday. On the average at the given stop come in 5 passengers, turns out -9 passengers.

The study of the performance of the route \#3A at the stop "Podatkova" (segment B) is shown in Fig. 8, 9.

As can be seen from the figures, the demand for passengers at the stop "Podatkova" (segment B) reaches a maximum of 10 passengers on Wednesday and a minimum of 1 passenger on Wednesday as well. The number of departing passengers reaches a maximum of 36 passengers on Friday and a minimum of 2 passengers on Friday as well. On the average at the given stop come in 4 passengers, turns out -12 passengers.

The study of the performance of the route No. 3A at the stop "Stryjska - Naukova" (segment B) is shown in Fig. 10, 11. 


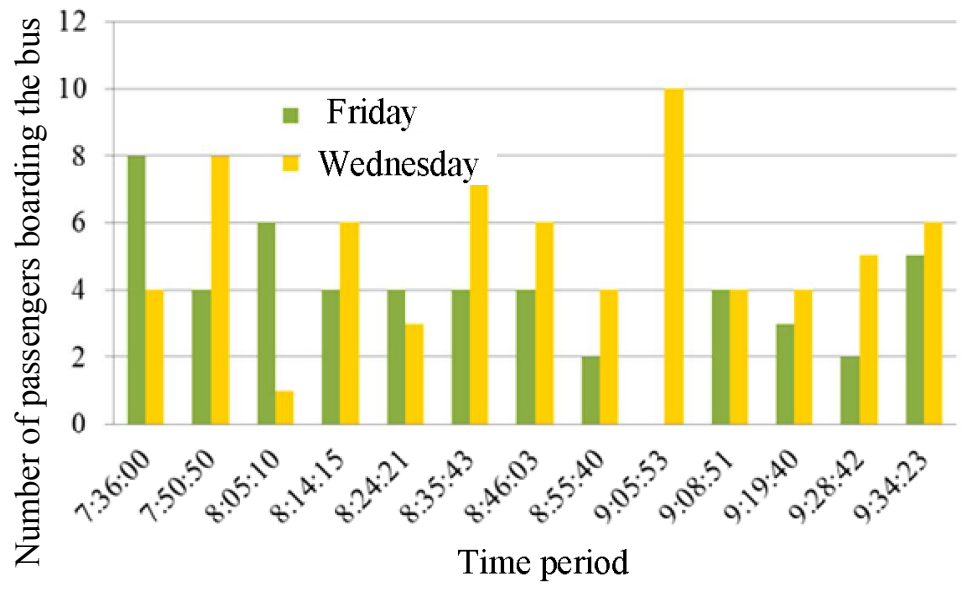

Fig. 8. Number of passengers boarding the bus \#3A at stop "Podatkova" (segment B)

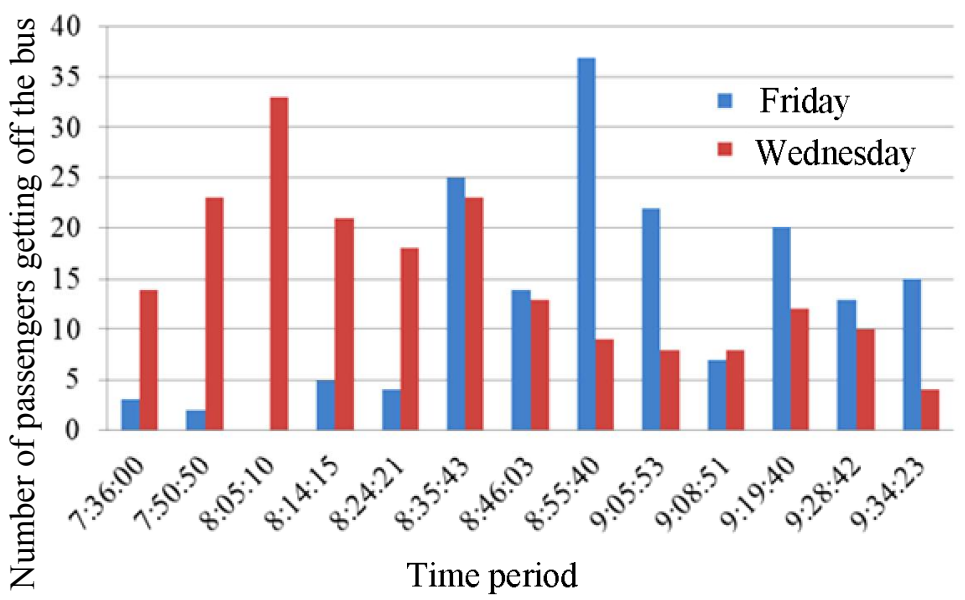

Fig. 9. Number of passengers getting off the bus \#3A at stop "Podatkova" (segment B)

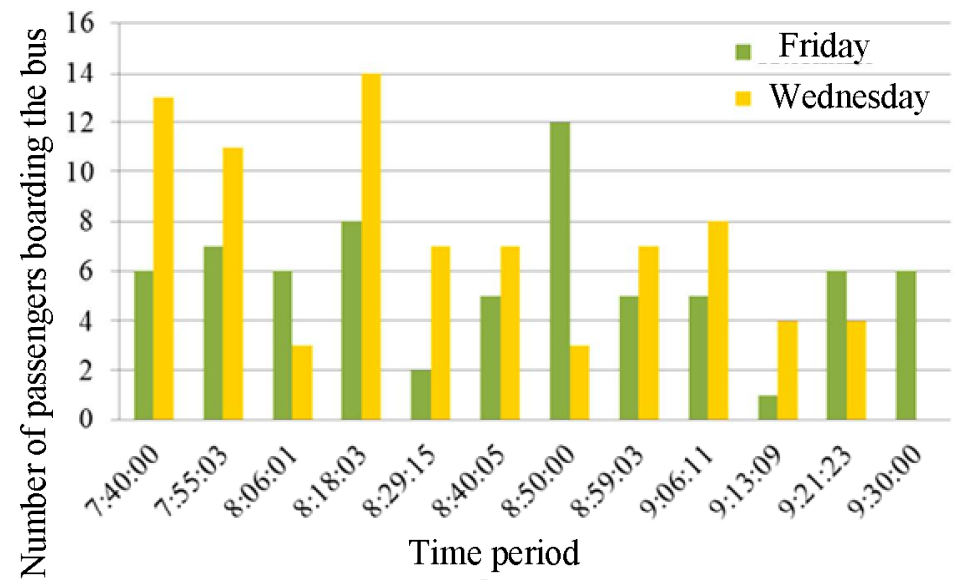

Fig. 10. Number of passengers boarding the bus \#3A at stop "Stryjska - Naukova" (segment B)

As can be seen from the figures, the demand for passengers at the stop "Stryjska - Naukova" (segment B) reaches a maximum of 14 passengers on Wednesday and a minimum of 1 passenger on Friday. The number of departing passengers reaches a maximum of 19 passengers on Friday and a 
minimum of 2 passengers on Friday as well. On the average at the given stop come in 6 passengers, turns out -10 passengers.

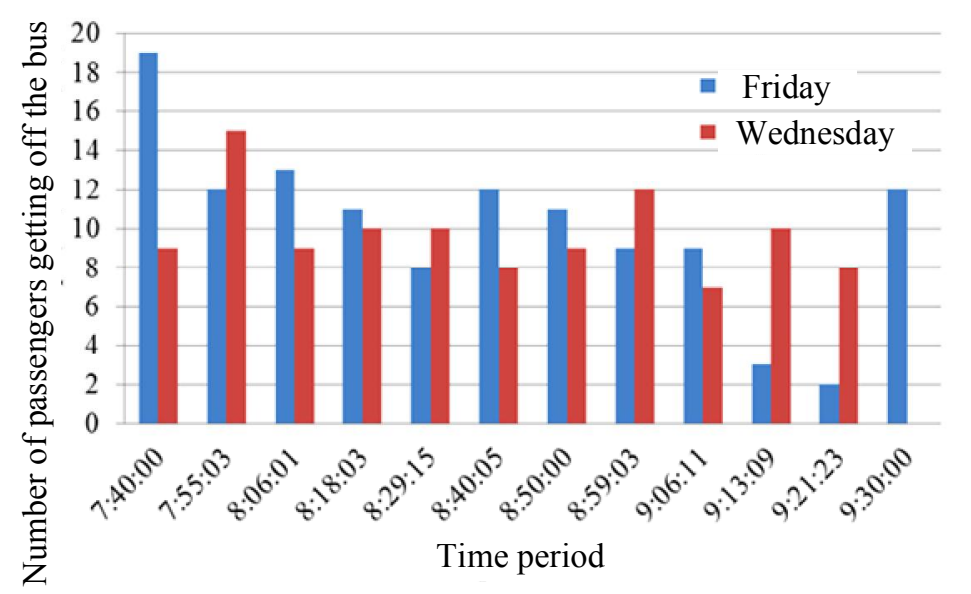

Fig. 11. Number of passengers getting off the bus $\# 3 A$ at stop "Stryjska-Naukova" (segment B)

The study of the performance of the route \#3A at the stop "Bus Station" (segment A) is shown in Fig. 12, 13.

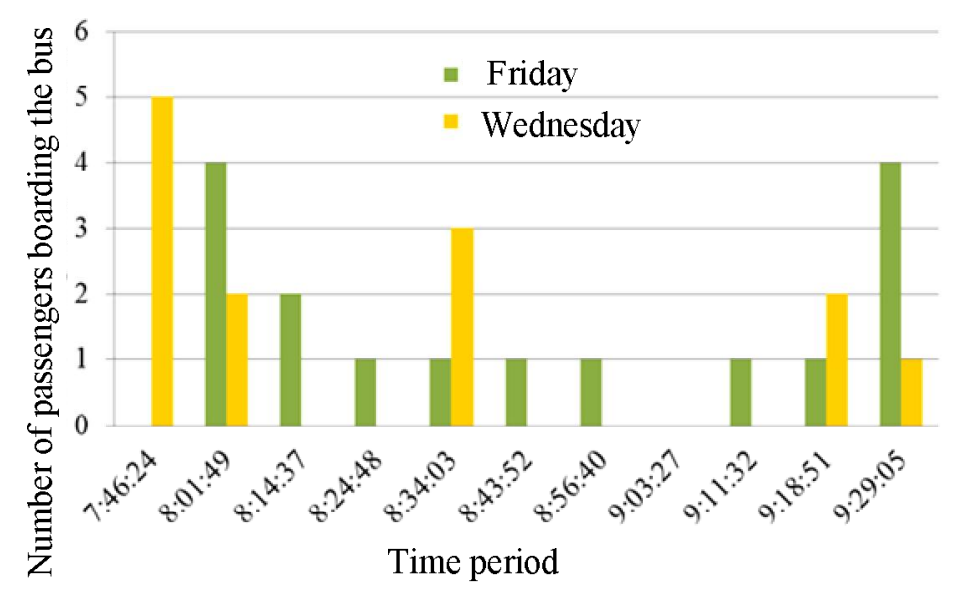

Fig. 12. Number of passengers boarding the bus \#3A at stop "Bus Station" (segment A)

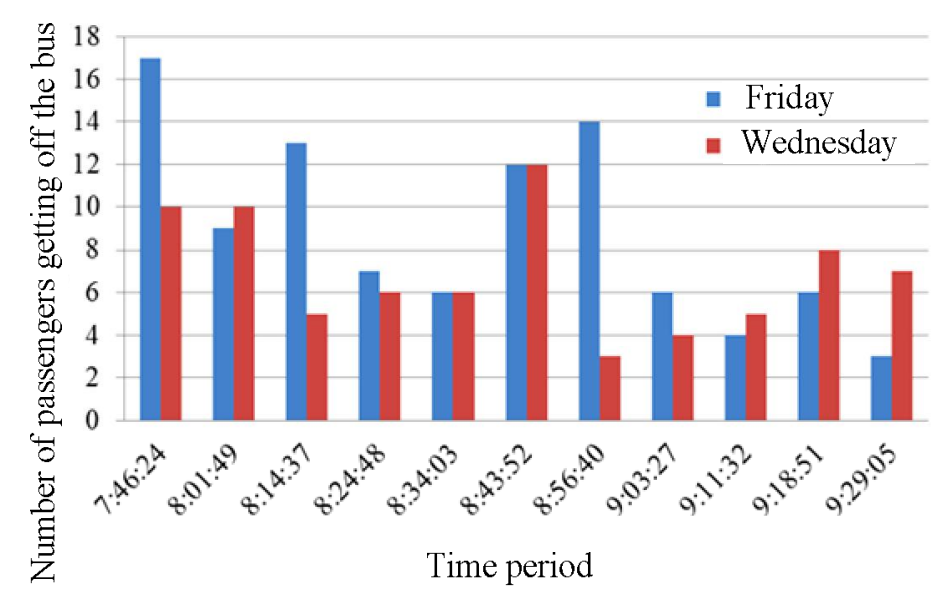

Fig. 13. Number of passengers getting off the bus \#3A at stop "Bus Station" (segment A) 
Demand for passengers at the stop "Bus station" (segment A) reaches a maximum of 5 passengers on Wednesday and a minimum of 1 passenger on Friday. The number of departing passengers reaches a maximum of 17 passengers on Friday and a minimum of 3 passengers on Friday as well. On the average at the given stop come in 2 passengers, turns out -9 passengers.

The study of the performance of the route \#3A at the stop of the shopping center "King Cross Leopolis" (segment A) is shown in Fig. 14.

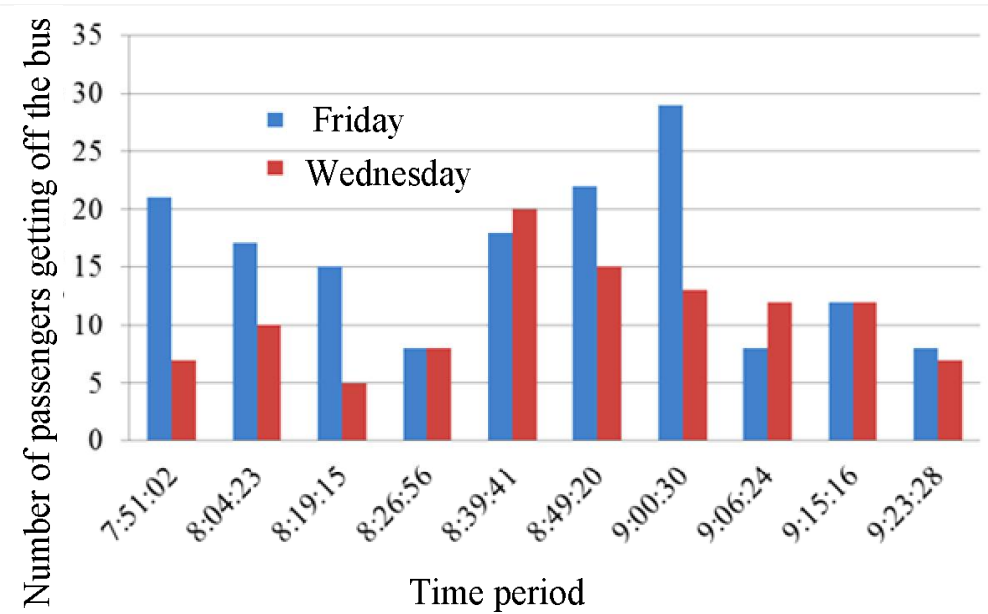

Fig. 14. Number of passengers getting

off the bus \#3A at stop of the shopping center "King Cross Leopolis"

(segment A)

The number of departing passengers reaches a maximum of 28 passengers on Friday and a minimum of 5 passengers on Wednesday. On the average at the given stop turns out - 16 passengers.

With the obtained data it is possible to estimate the demand of passengers at stops, depending on where the stop is located, its type, alternative routes and ets.

\subsection{Study of bus dwelling time}

Similar to the demand of passengers at stops, the duration of the bus stop at the studied stops is determined. The results of the duration of the dwelling time at the stop "Prospekt Svobody" (segment C) are shown in Fig. 15.

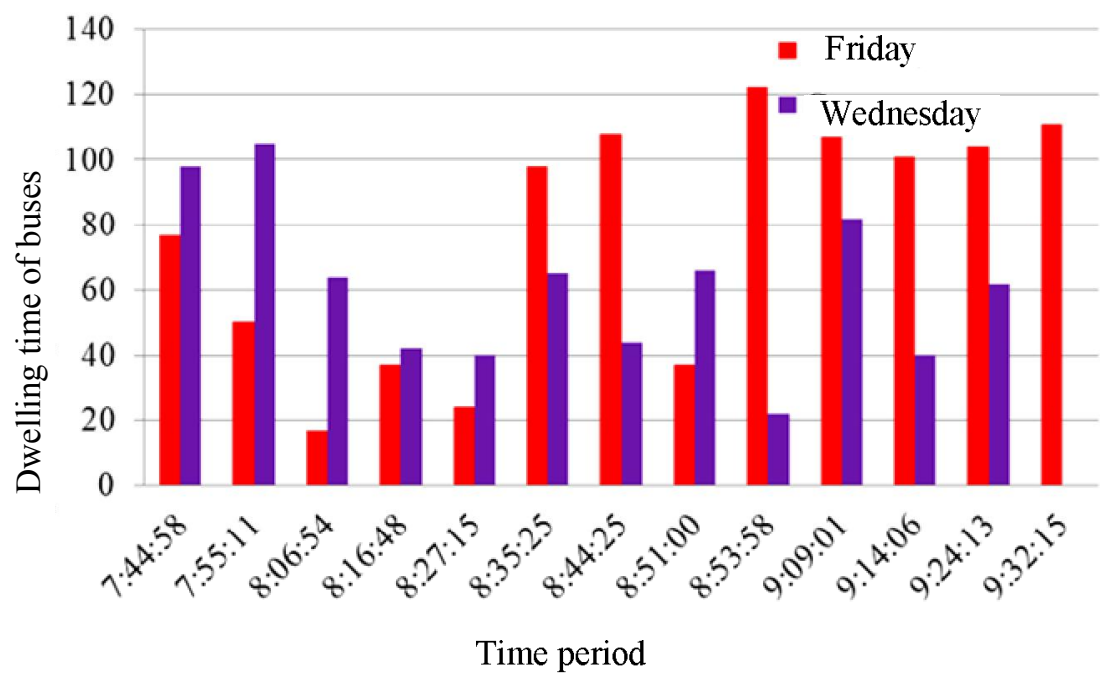

Fig. 15. Duration of the bus stop at

the stop "Prospekt Svobody" (segment C) in the study period 
As can be seen from Figure 15, the duration of the dwelling time at this stop was a maximum of 2 minutes, a minimum of less than 20 seconds. The average dwelling time at this stop was 76 seconds.

The results of the duration of the dwelling time at stop "Shota Rustaveli" (segment C) are shown in Fig. 16.

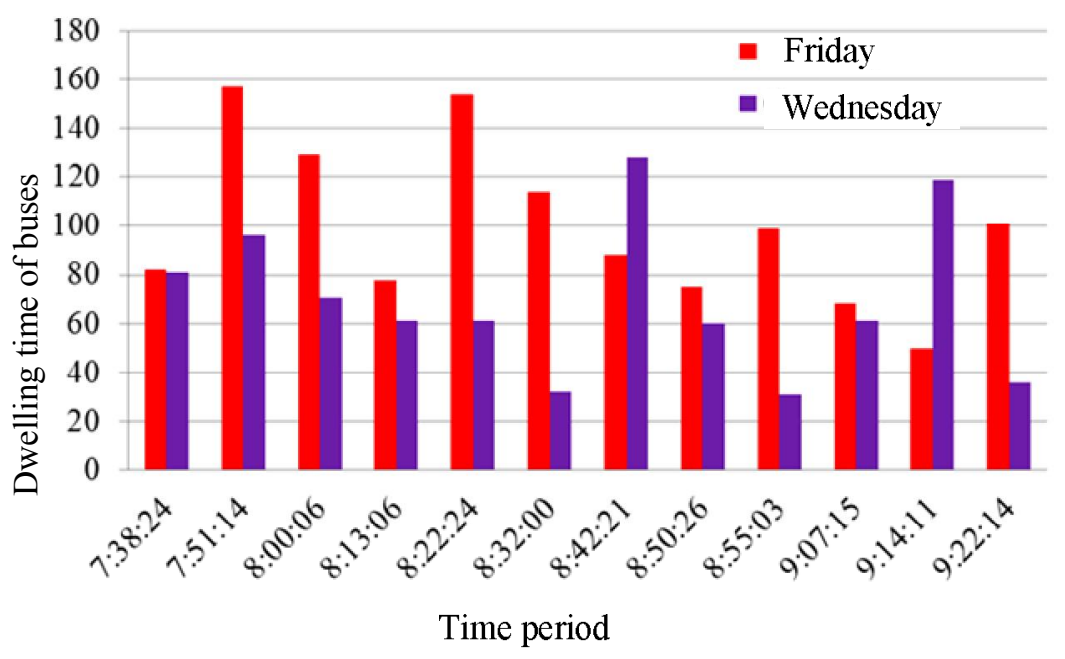

Fig. 16. Duration of the bus stop

at the stop "Shota Rustaveli" (segment C) in the study period

As can be seen from Figure 16, the duration of the dwelling time at this stop was a maximum of 160 seconds, a minimum of 30 seconds. On average, dwelling time was at this stop 100 seconds.

The results of the duration of the dwelling time at the stop "Childrens Railway" (segment B) are shown in Fig. 17.

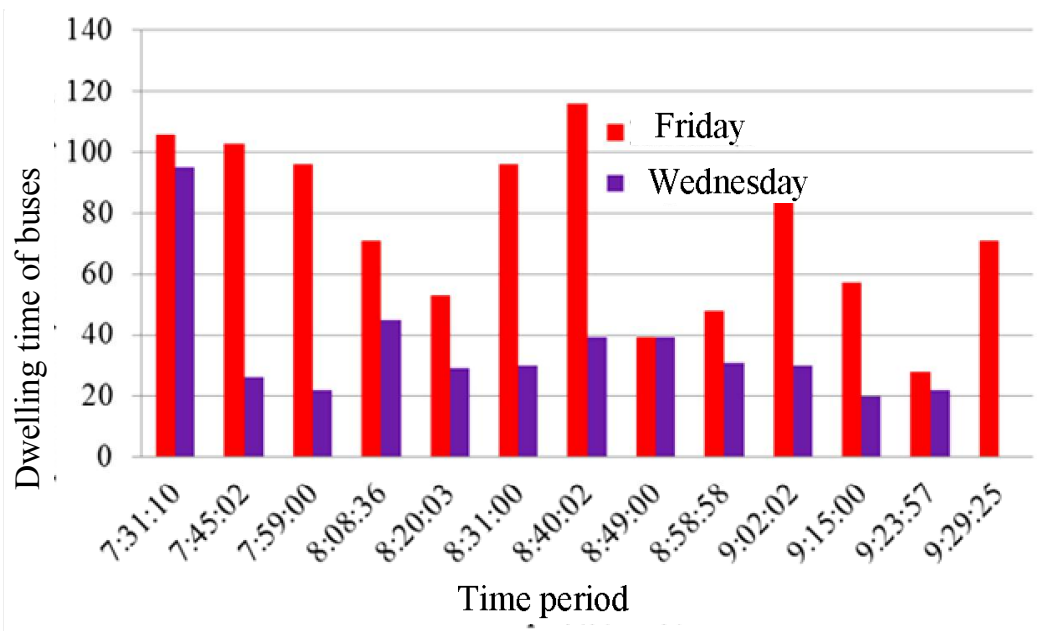

Fig. 17. Duration of the bus stop

at the stop "Childrens Railway" (segment B) in the study period

As can be seen from Figure 17, the duration of the dwelling time at this stop was a maximum of 120 seconds, a minimum of 20 seconds. The average dwelling time at this stop was 75 seconds.

The results of the duration of the dwelling time at the bus stop "Podatkova" (segment B) are shown in Fig. 18.

As can be seen from Figure 18, the duration of the dwelling time at this stop was a maximum of 60 seconds, a minimum of 14 seconds. The average dwelling time at this stop was 34 seconds.

The results of the duration of the dwelling time at the stop "Stryjska - Naukova" (segment B) are shown in Fig. 19. 


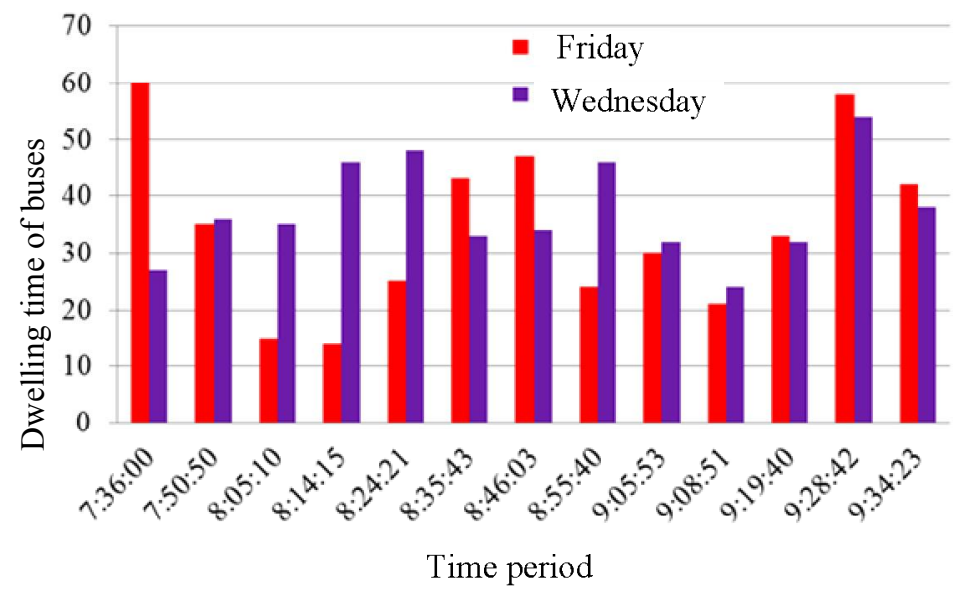

Fig. 18. Duration of the bus stop

at the stop "Podatkova" (segment B) in the study period

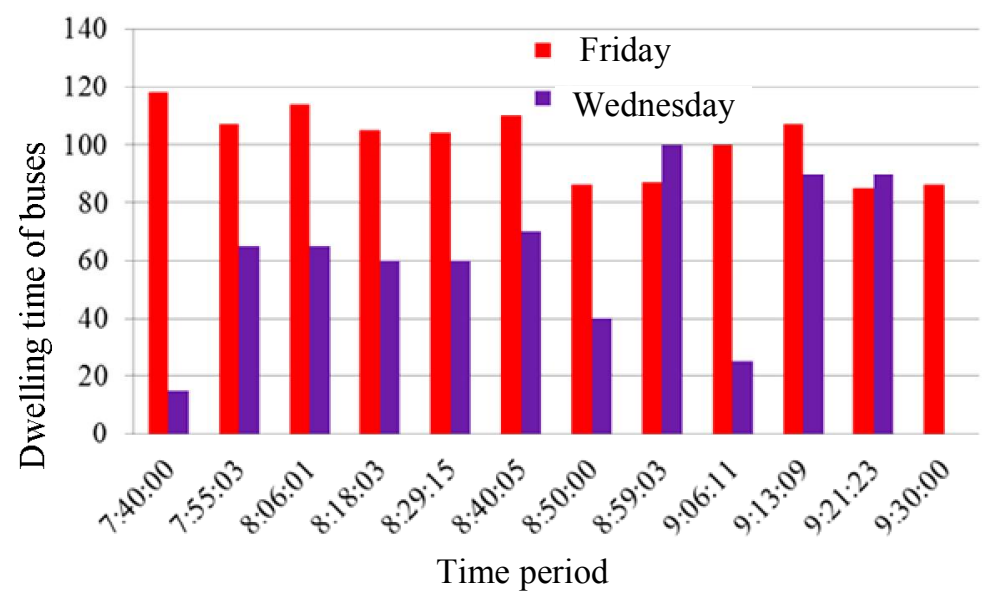

Fig. 19. Duration of the bus stop

at the stop "Stryjska - Naukova" (segment B) in the study period

As can be seen from Figure 19, the duration of the dwelling time at this stop was a maximum of 120 seconds, a minimum of 16 seconds. The average dwelling time at this stop was 100 seconds.

The results of the duration of the bus stop "Bus station" (segment A) are shown in Fig. 20.

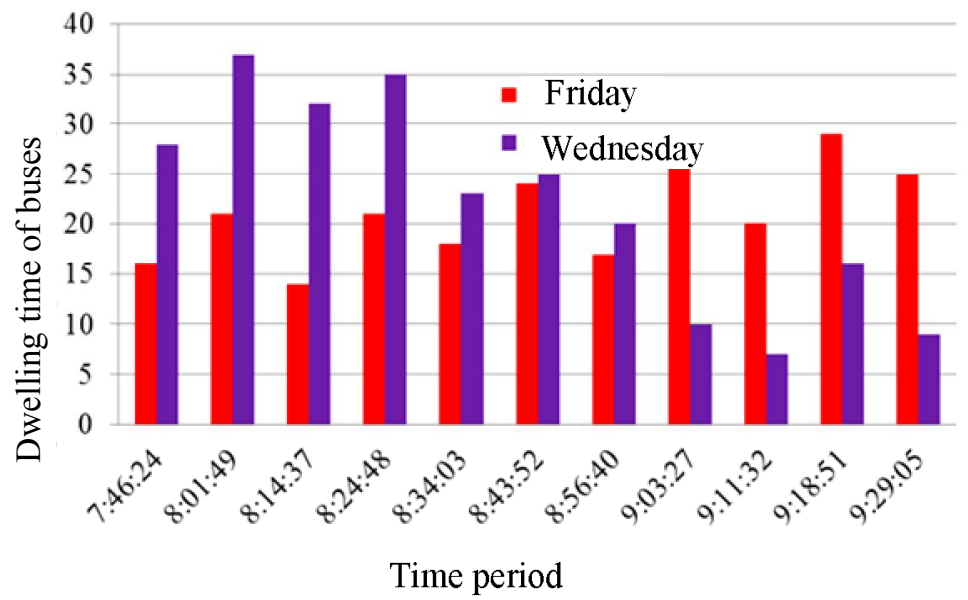

Fig. 20. Duration of the bus stop

at the stop "Bus station" (segment B) in the study period 
The duration of the dwelling time at this stop was a maximum of 40 seconds, a minimum of 7 seconds. The average dwelling time at this stop was 21 seconds.

From these figures it can be concluded that according to the nature of the behavior of buses at the stop, the passenger demand at the stops, the typical studied stops can be grouped into groups and segments.

\subsection{Determining the dependence of the demand of passengers on dwelling time at stops}

Data on the duration of the bus trip were obtained from GPS data and refer to the working days of each week [7]. The data collected include the time of arrival and departure from each stop under study, as well as data on passenger demand at each stop. The obtained data were also modeled in the software PTV "VISSIM 8".

The results of modeling the dwelling time and the demand of passengers are shown in Fig. 21.

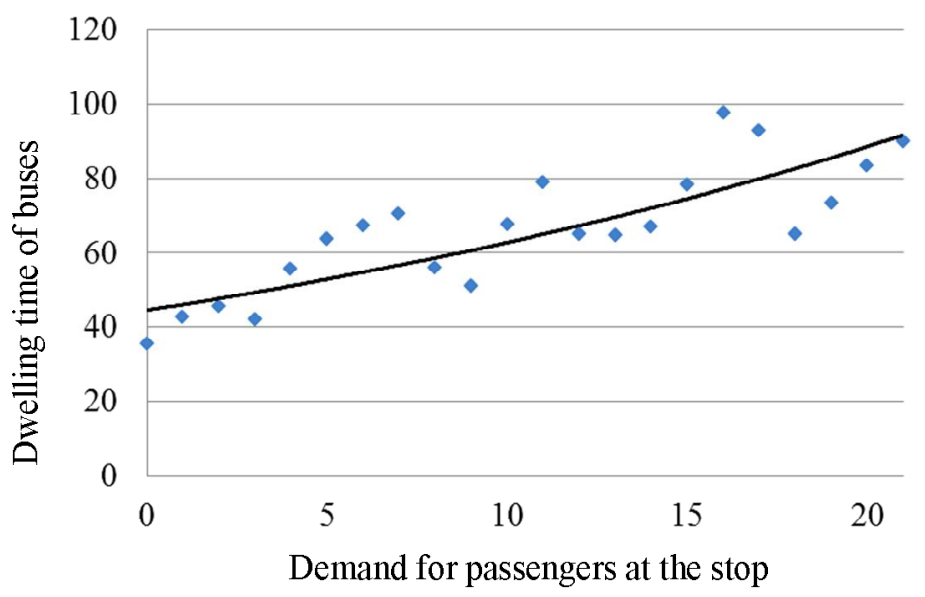

Fig. 21. Dependence of the demand of passengers for transportation on the dwelling time

These results provide an opportunity to obtain data on the length of stay of buses at stops. As you can see from the figure, the average length of dwelling time at the stop varies from 40 to 100 seconds when the demand of passengers are 21 . When analyzing the data, it was also found that on average at each stop in the morning peak period was observed from 1 to 10 passengers. More than 10 passengers at stops were observed in $15 \%$ of the whole sample of values. In addition, depending on the dependence of the increasing influence of passenger traffic on the duration of the bus stop.

The total demand of passengers at all stops was also analyzed. A number of values of the number of passengers who used the bus \#3A are derived. Fig. 22 shows the distribution of passenger demand.

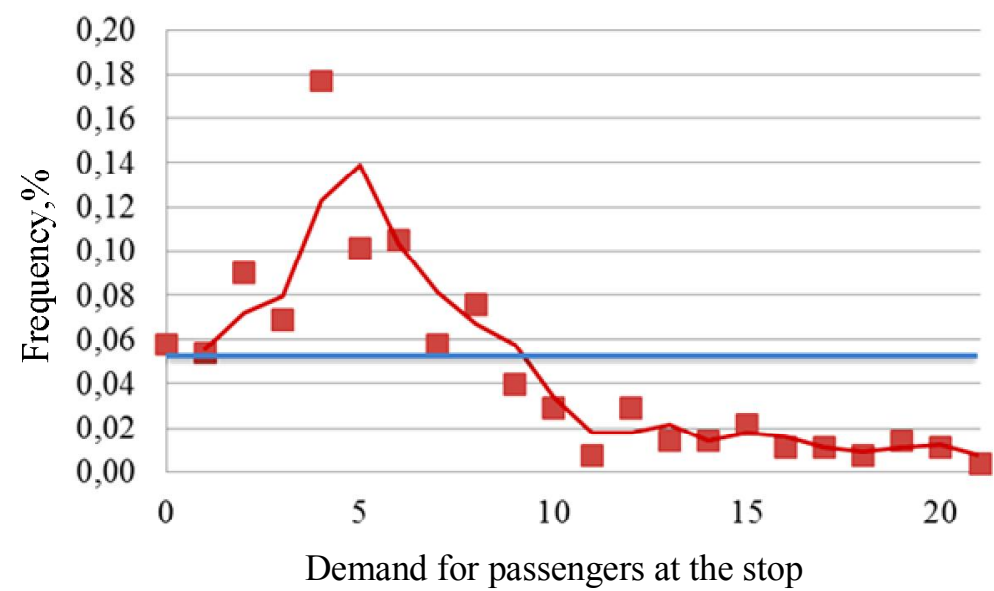

Fig. 22. Passenger demand at stops on the route \#3A 
The histogram shows that the predominant number of passengers is about 5 people. The predominant number of passengers ranged from 1 to 9 people. More than 10 people were observed very rarely.

A cumulative distribution of passenger demand was also constructed (Fig. 23).

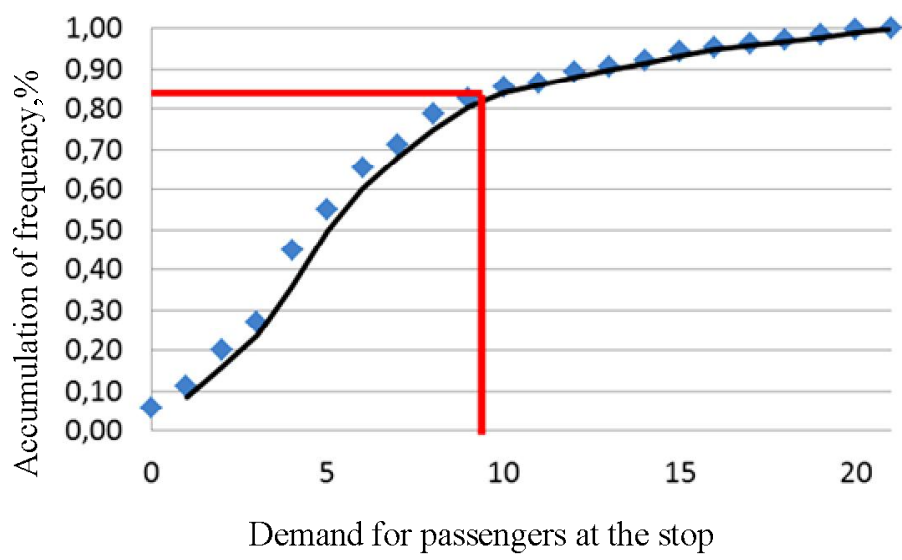

Fig. 23. Cumulative demand of passengers at stops on the route \#3A

It is seen that for $85 \%$ of the provision the number of passengers using this mode of transport is from 1 to 9 people.

The proposed segmental approach for forecasting the travel time of the bus, taking into account the determination of the time spent at the stop can increase the accuracy of forecasting the total duration of the route on the road under different conditions. It is possible to determine both the impact of traffic conditions and the demand for transportation on the duration of the bus in real time.

\section{CONCLUSIONS AND RESEARCH PERSPECTIVES}

In summary, the main contributions of the proposed approach are described below:

1. The use of Intelligent Transport Systems in urban conditions is one of the solutions to reduce congestion of vehicles and the amount of harmful emissions. An important component of ITS is the assessment of the duration of a public transport trip. This system most accurately provides real-time passenger travel information. An intelligent system to change pre-set schedules can reduce the total duration of movement. And this can potentially increase the demand for passengers at public transport stops.

2. To improve the quality of public transport services, it is necessary to focus on the study of the duration of the bus (the duration of traffic between stops and the dwelling time). In this paper, the authors focus on determining the dependence of the duration of buses at stops depending on the demand of passengers.

3. After receiving this information, system operators can design and adjust the data according to the estimated duration of the trip. Many existing studies predicting the duration of a bus trip have achieved varying degrees of success. However, the continuation of these studies will make it possible to more accurately predict the duration of travel by bus.

4. The dwelling time of buses at stops is not considered independent of the duration of the journey. The duration of the bus is the periods of time when the buses wait at the stops, and the travel time, which is the duration of the bus between each two stops. The duration of the bus significantly affects the number of passengers who get on and off, which differs from the travel time, which depends on local traffic conditions.

5. The dwelling time at the stop is more unstable and has various reasons. This has a significant impact on the overall duration of the bus. Therefore, there is a need to study the time spent by buses at stops, taking into account the demand of passengers for transportation. The study was conducted on the bus route \#3A in Lviv. To determine the dwelling time of the bus at stops, it is 
necessary to take into account information about passengers and the trajectory of buses. The obtained data can increase the accuracy of forecasting in different traffic situations in comparison with the most modern methods.

\section{References}

1. Berezny R. \& Konecny V. (2017). The impact of the quality of transport services on passenger demand in the suburban bus transport. Elsevier, \#192. - P. 40-45. (in Ukrainian).

2. Gurmu Z., Fan W. (2014). Artificial neural network travel time prediction model for buses using only gps data. Public Transport. 17, P. 3. (in English).

3. Yang M., Chen C., Wang L., Yan X., Zhou L. (2016). Bus arrival time prediction using support vector machine with genetic algorithm. Neural Network World 26. 205 P. (in English).

4. Bai C., Peng Z., Lu Q., Sun J. (2015). Dynamic bus travel time prediction models on road with multiple bus routes. Comput. intell. Neurosci. P. 63. (in English).

5. Xu H., Ying J. (2017). Bus arrival time prediction with real-time and historic data. Clust. Comput. 20. P. 3099-3106. (in English).

6. Zhou M., Wang D., Li Q., Yue Y., Tu W., Cao R. (2017). Impacts of weather on public transport ridership: Results from mining data from different sources. Transport. Res. Part C: Emerg. Technol. 75. P. 17-29. (in English).

7. Cheng Z., Chow M., Jung D., Jeon J. (2017). A big data based deep learning approach for vehicle speed prediction. In: 2017 IEEE 26th International Symposium on Industrial Electronics (ISIE). IEEE. P. 389-394. (in English).

8. Ma Z., Koutsopoulos H., Ferreira L., Mesbah M. (2017). Estimation of trip travel time distribution using a generalized markov chain approach. Transport. Res. Part C: Emerg. Technol. 74. P. 1-21. (in English).

9. Kumar B., Vanajakshi L., Subramanian S. (2017). Bus travel time prediction using a time-space discretization approach. Transport. Res. Part C: Emerg. Technol. 79. P. 308-332. (in English).

10. Brakewood C., Macfarlane G., Watkins K. (2015). The impact of real-time information on bus ridership in new york city. Transport. Res. Part C: Emerg. Technol. 53. P. 59-75. (in English).

11. Rahman M., Wirasinghe S., Kattan L. (2018). Analysis of bus travel time distributions for varying horizons and real-time applications. Transport. Res. Part C: Emerg. Technol. 86. P. 453-466. (in English).

12. Comi A., Nuzzolo A., Brinchi S. and Verghini R. (2017). Bus dispatching irregularity and travel time dispersion. $5^{\text {th }}$ IEEE International Conference on Models and Technologies for Intelligent Transportation Systems (MT-ITS). pp. 856-860. doi: 10.1109/MTITS.2017.8005632 (in English).

13. Fusco G., Colombaroni C. and Isaenko N. (2016). Short-term speed predictions exploiting big data on large urban road networks. In: Transportation Research Part C: Emerging Technologies 73, pp.183-201. (in English).

14. Comi A., Nuzzolo A., Brinchi S., Verghini R. (2017). Bus travel time variability: some experimental evidences. Transportation Research Procedia 27, pp. 101-108. (in English).

15. He P., Jiang G., Lam S. and Tang D. (2019). Travel-Time Prediction of Bus Journey With Multiple Bus Trips. IEEE Trans. on Intelligent Transportation Systems. (in English).

16. Moreira-Matias L., Mendes-Moreira J., de Sousa J., Gama J. (2015). Improving Mass Transit Operations by Using AVL-Based Systems: A Survey. IEEE Transactions on Intelligent Transportation System, doi: 10.1109/TITS.2014.2376772. (in English).

17. Shalaby A. and Farhan A. (2003). Bus travel time prediction model for dynamic operations control and passenger information systems. Transp. Research Board 2. (in English).

18. Cats O. (2019). Determinants of bus riding time deviations: Relationship between driving patterns and transit performance. Journal of Transportation Engineering Part A: Systems 145(1),04018078. (in English).

19. Hyndman R. and Athanasopoulos G. (2018). Forecasting: principles and practice. Second edition. www.otexts.org. (in English).

Received 27.08.2020; Accepted in revised form 29.09.2020. 